\title{
Studi Aliran Beban Interkoneksi Sistem Sulbangsel hingga Tahun 2020 Berdasarkan RUPTL PT. PLN (Persero) 2017-2026
}

\author{
Muhira Dzar Faraby ${ }^{*}$, Ontoseno Penangsang ${ }^{2}$ \\ Doctoral Student Electrical Engineering, ITS, Surabaya ${ }^{I}$ \\ Electrical Engineering, ITS, Surabaya ${ }^{2}$ \\ *e-mail: muhira_faraby@yahoo.com
}

\begin{abstract}
This research aims to predict the condition of the electrical system Sulbangsel Systems Interconnection based RUPTL PT. PLN (Persero) from 2017 to 2026. Methods used power flow by using the Newton-Raphson M.File on Matlab Simulink based IEEE 33 Bus. Extra Power, Line Transmission and Load based RUPTL and improvement of existing load conditions using linear regression of the latest data by $11.7 \%$ annually. Results obtained an increase in bus point that initially 45 buses to 60 buses. Predicted by the addition of generation, transmission and load point by RUPTL there are 4 spot bus has a voltage level below 0.9 pu and total losses obtained up to $63+j 288.81$ MVA.
\end{abstract}

Keywords :Robot, Arduino, Floor Cleaners, Line Follower

\begin{abstract}
Abstrak
Penelitian ini bertujuan untuk memprediksikan kondisi sistem kelistrikan Interkoneksi Sistem Sulbangsel berdasarkan RUPTL PT. PLN (Persero) 2017-2026. Metode aliran daya yang digunakan Newton-Raphson dengan menggunkan M.File pada Simulink Matlab berdasarkan Standar IEEE 33 Bus. Penambahan Pembangkit, Saluran Transmisi dan Pembebanan berdasarkan RUPTL dan peningkatan kondisi beban yang telah ada menggunakan regresi linear dari data terakhir sebesar $11.7 \%$ tiap tahunnya. Hasil yang didapatkan adanya peningkatan titik bus yang awalnya 45 bus menjadi 60 bus. Diprediksikan dengan adanya penambahan pembangkit, saluran transmisi dan titik beban berdasarkan RUPTL masih terdapat 4 titik bus memiliki level tegangan dibawah 0.9 pu dan total lossis yang didapatkan hingga $63+\mathrm{j} 288.81$ MVA.
\end{abstract}

Kata kunci :RUPTL, Newton-Raphson, Losses

\section{Pendahuluan}

Perkembangan teknologi dari tahun ke tahun diikuti dengan perkembangan akan kebutuhan energi listrik suatu daerah. Kebutuhan akan energi listrik yang berupa daya aktif maupun daya reaktif juga bervariatif dari waktu ke waktu dan keberadaan beban yang ada dalam suatu sistem kelistrikan.

Keperluan penyediaan tenaga listrik bagi para pelanggan, diperlukan berbagai peralatan listrik yang dihubungkan satu sama lain yang mempunyai inter relasi secara keseluruhan membentuk suatu sisten tenaga listrik. Yang dimaksud dengan sistem tenaga listrik disini adalah sekumpulan pusat listrik dan gardu induk (Pusat Beban) yang satu sama lain yang dihubungkan dengan jaringan transmisi sehingga merupakan sebuah kesatuan interkoneksi.

Perencanaan pengadaan dan instalasi suatu peralatan tenaga listrik yang akan dihubungkan dalam suatu sistem kelistrikan harus mempertimbangkan tiga aspek yaitu mutu atau kualitas, ekonomis dan keandalannya. Mutu dan kualitas peralatan yang akan dipasang harus mampu mempertahankan standar frekuensi dalm hal pengontrolan daya reaktif dan tegangan dalam hal pengotrolan daya reaktif suatu sistem sesuai batas yang diizinkan. Handal dalam artian peralatan tersebut mampu bekerja sesuai dengan fungsinya meskipun adanya perubahan beban ataupun adanya gangguan sesaat yang terjadi. Peralatan yang mempunyai kualitas dan keandalan yang baik mempunyai harga 
yang sangat mahal dengan kata lain sulit untuk mempertemukan ketiga aspek diatas sehingga didapatkan hasil yang optimal.

Untuk memproyeksi sistem kelistrikan hingga beberapa tahun kedepanya didasari dengan data sistem kelistrikan beberapa tahun terakhir akan tetapi perkembangan beban industry itu terkadang melenceng dari proyeksi yang ada. Hal ini di buktikan dengan adanya pengadaan smelter di dua titik berdasarkan aturan pemerintaha tentang pengolahan hasil bumi dan pengadaan unit pembangkit khususnya berbasis energi terbarukan itu didasari dengan ketersediaan energi primer yang ada yang disusunlah dalam suatu RUPTL yang melihat potensi potensi yang ada.

Pada penelitian ini kita akan mencoba menganalisis studi aliran daya interkoneksi Sistem Sulbengsel yang diproyeksikan berdasarkan RUPTL hingga tahun 2020.

\section{Metoda Penelitian}

\subsection{Studi Aliran Daya}

Pada penelitian ini untuk menghitung aliran beban digunakan metode NewtonRaphson. Perhitungan aliran daya menggunakan software MATLAB 2010 yang mengacu pada pengembangan perhitungan aliran daya Hadi-Saddat 33 bus. Data sekunder yang kita gunakan merupakan data beban harian UPT Penyaluran Sistem Sulbangsel PT. PLN (Persero) interkoneksi 45 bus pada tanggal 4 Februari 2017 pada kondisi beban puncak malam hari.

\subsection{Proyeksi Sistem Kelistrikan}

Proyeksi hingga tahun 2020 dengan penambahan titik bus, titik dan kapasitas pembangkit, saluran transmisi, dan perkembangan beban $11.7 \%$ berdasarkan RUPTL PT. PLN (Persero) 2017-2026 sehingga didapatkan 60 jumlah bus. Adapun penambahan unit pembangkit berupa PLTGU Makassar Peaker 450 MW, PLTU Jeneponto 200 MW dan PLTU Barru 100 MW, PLTB Sidrap 70 MW dan PLTB Jeneponto 63 MW, PLTM Tersebar 67.85 MW. Penambahan titik bus berupa 1 bus pembangkit, 1 bus trafo IBT, 13 bus beban.

Penambahan 13 line transmisi baik $150 \mathrm{kV}$ dan $275 \mathrm{kV}$ yang mengubah konfigurasi jaringan dimana perhitungan nilai impedansi untuk trafo iBT dapat dihitung dengan kapasitas trafo yang terpasang dan impedansi saluran transmisi dapat diberikan dengan melakukan pendekatan nilai berdasarkan panjang saluran transmisi yang akan di pasang berdasarkan saluran transmisi yang ada sebelumnya.

\subsection{Diagram Alir Penelitian}

Adapun diagram alir penelitian dapat dilihat pada gambar 1 dibawah ini.

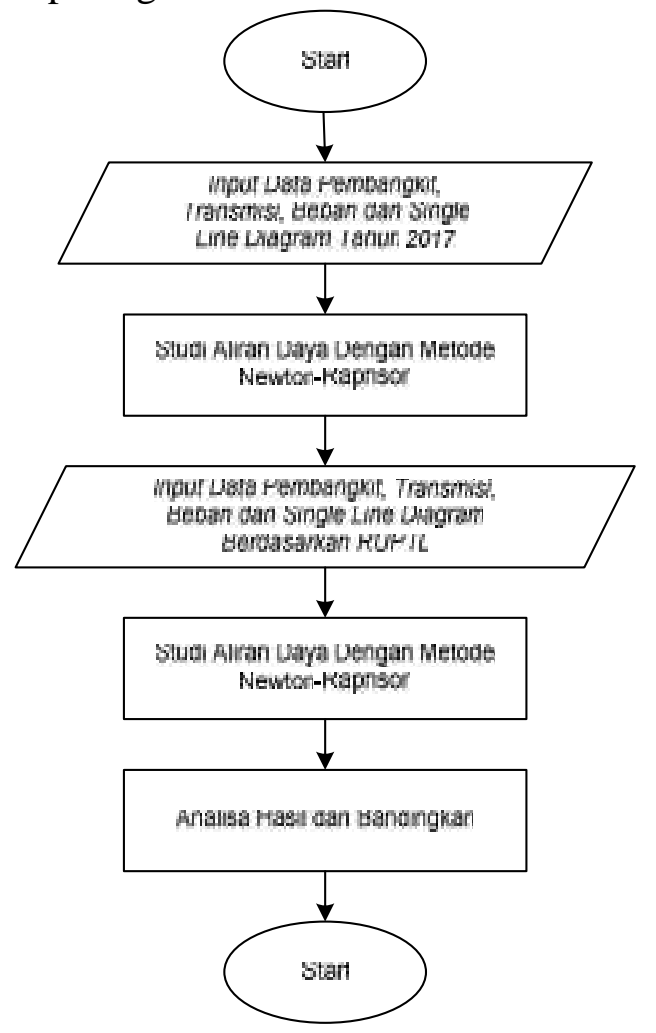

Gambar 1. Diagram Alir Penelitian

\section{Hasil dan Pembahasan}

Adapun hasil aliran daya didapatkan pada kondisi 2017 dan kondisi proyeksi pada tahun 2020 berdasarkan RUPTL PT. PLN (Persero).

Perbandingan nilai level tegangan bada tiap-tiap bus pada tahun 2017 dan 2020 dapat dilihat pada gambar 2 . 


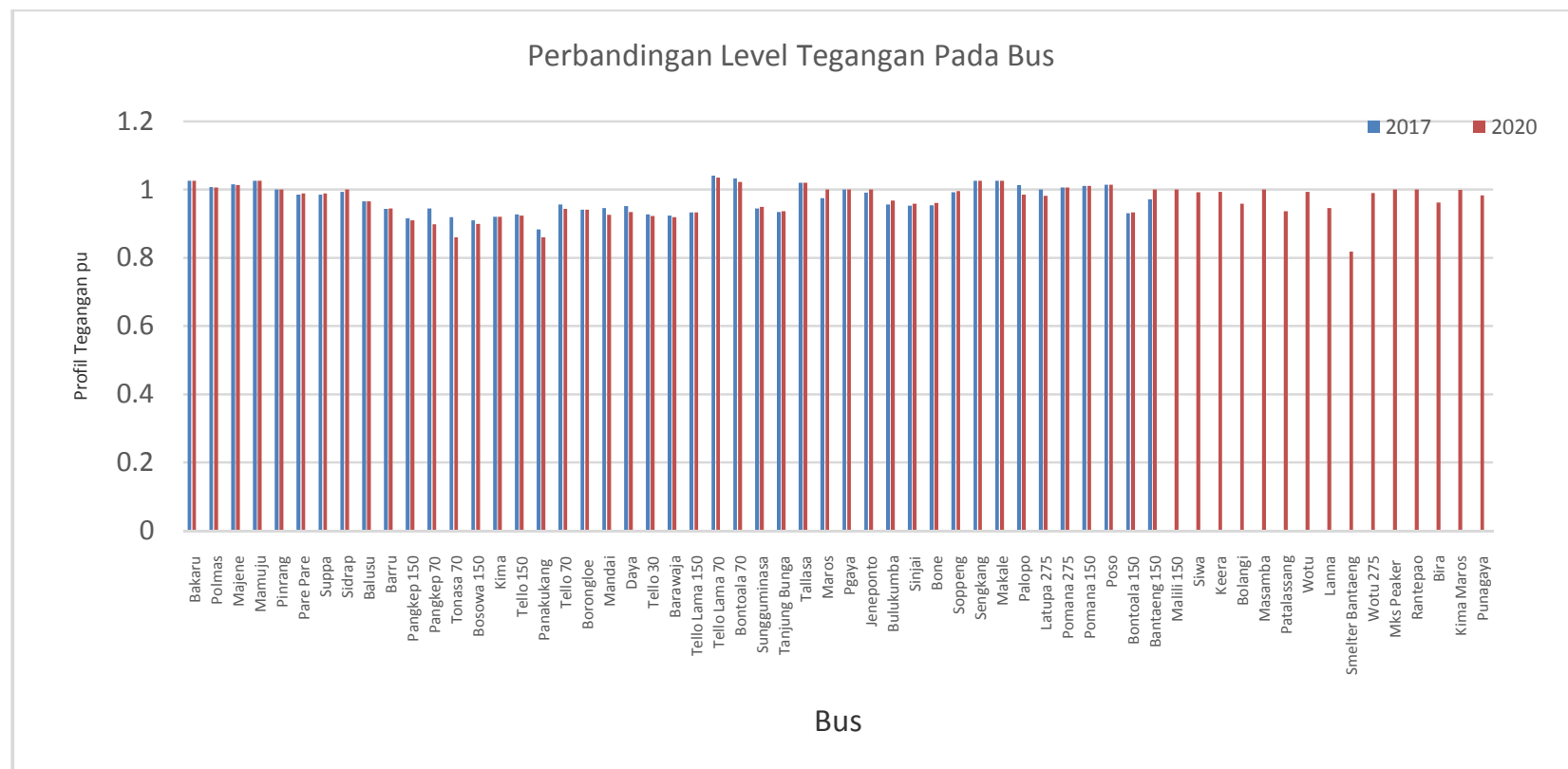

Gambar 2. Perbandingan Level Tegangan pada Tiap tiap Bus pada Tahun 2017 dengan 2020.

Pada gambar 2 diatas terlihat kondisi sistem kelistrikan Sulbangsel masih terdapat 4 titik bus yang berada pada 0.9 pu. Bus tersebut berupa Smelter Bantaeng, Pangkep $70 \mathrm{kV}$ dan Tonasa $70 \mathrm{kV}$ yang merupakan daerah kawasan industri pertambangan dan semen dan bus Panakukang yang merupakan bus penampung beban di pusat kota selain itu beberapa titik bus mengalami perbaikan nilai level tegangan mendekati $1 \mathrm{pu}$.

Adapun total losses yang dihasilkan dapat dilihat pada gambar 3 .

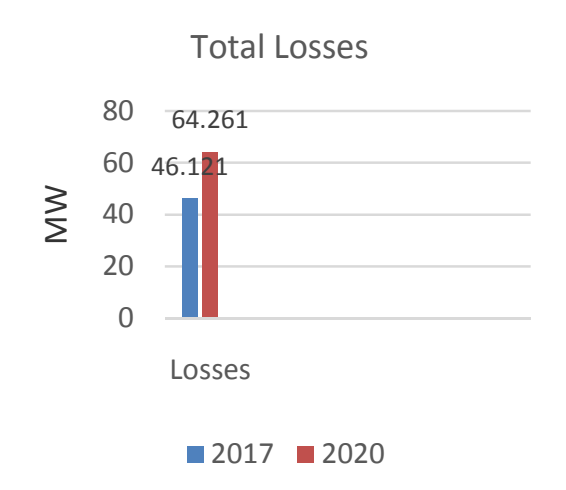

Gambar 3. Perbandingan Lossis Saluran Transmisi.
Adanya peningkatan nilai losses saluran transmisi dari 46.121 MW menjadi 64.261 MW dikarenakan adanya pengembangan kebutuhan beban yang menyebabkan arus yang mengalir besar dan lossis juga meningkat.

Pemilihan swing / slack bus pada sistem ini yaitu bus Sengkang dikarenakan pada bus ini beban yang di suplai dengan kapasitas besar dan respon frekuensi terhadap perubahan beban juga baik dikarenaan pada bus ini terdapat unit pembangkit PLTGU dengan kapasitas 315 MW. Adapun respon pembangkit pada bus ini dapat dilihat pada gambar 4 . 


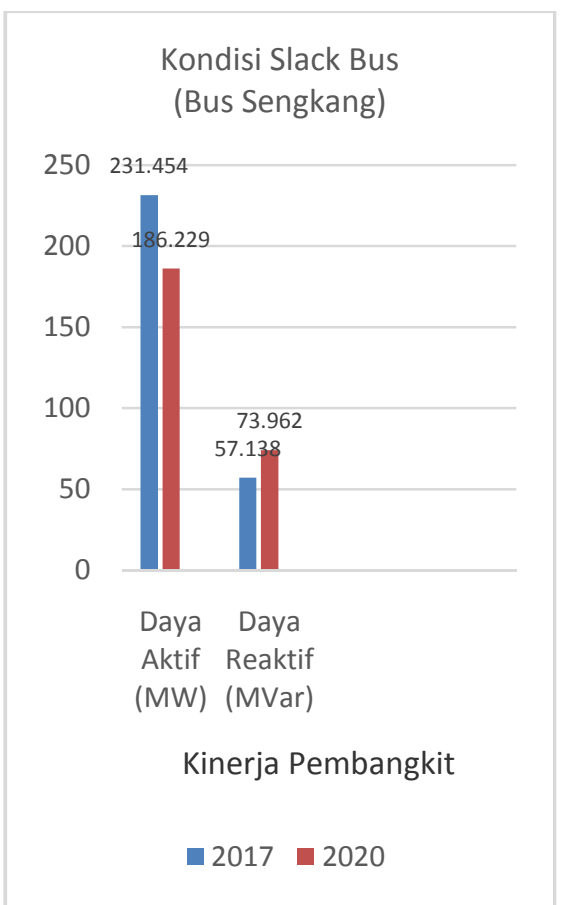

Gambar 4. Perbandingan Pasokan daya aktif dan reaktif PLTGU Sengkang.

Terlihat pada gambar 4 adanya penurunan suplai daya aktif pada PLTGU Sengkang dari 231.454 MW menjadi 186.22 dikarekan adanya suplai dari beberapa penambahan unit pembangkit yang telah tersebar di beberapa titik terkhusus di pusat beban (perkotaan dan industr). Adanya penempatan PLTU Makassar Peaker pada daerah pusat beban dapat memberikan solusi dalam permasalah sistem kelistrikan Sulbangsel yang dikenal dengan bottle neck yang membuat lossis saluran transmisi meningkat. Tetapi suplai daya reaktif meningkat dari 57.138 MVar menjadi 73.692 MVar. Hal ini dikarenakan dalam RUPTL tidak adanya perencenaan penambahan peralatan kompensasi daya reaktif baik dalam bentuk kapasitor ataupun FACTS Devices lainnya sehingga membuat semua unit unit pembangkit harus menyuplai lebih daya reaktif yang ada berdasarkan kebutuhan beban terkhususnya adanya pembangunan 2 unit beban industri berskala besar berupa smelter yang ada di Bantaeng dan Keera.

\section{Kesimpulan}

Adapun kesimpulan yang dapat ditarik pada penelitian ini yaitu :adanya beberapa bus yang masih dibawah 0.9 pu disebabkan pengembangan beban industri dengan penambahan pembangkit yang tidak disertai dengan penambahan peralatan kompensasi daya reaktif. Dan peningkatan lossis jaringan transmisi dikarenakan kebutuhan energi listrik juga meningkat. Dan penempatan unit pembangkit berupa PLTU Makassar Peaker dan PLTB Jeneponto dapat menjawab permasalahan sistem kelistrikan Sulbangsel berupa bottle neck.

\section{Saran}

Berdasarkan hasil penelitian didapatkan disarankan untuk penggunaan sebuah metode matematis atau kecerdasan buatan untuk mengoptimalkan kinerja pembangkit agar didapatkan kondisi sistem kelistrikan yang lebih optimal sesuai dengan standar yang diizinkan, serta peninjauan kembali terhadap pemilihan slack bus untuk unit pembangkit yang telah ada dan perencanan penembahan peralatan kompensasi daya reaktif pada titik-titik tertentu.

\section{DaftarPustaka}

[1] Tim Opsis, "Laporan Harian Real Time Sistem Kelistrikan Sulselrabar", UPT Sistem Sulsel PT. PLN (Persero), Makassar, 2017.

[2] Kementrian ESDM, “RUPTL PT. PLN Tahun 2017-2026 “, Jakarta, 2017.

[3] William D. \& Stevenson Jr., "Analisis Sistem Tenaga Listrik”, Penerbit Erlangga, Jakarta, 1983.

[4] Muhira Dzar Faraby, "Optimasi Penempatan SVC Pada Sistem Kelistrikan Sulselbar Dengan Menggunakan Algoritma Genetika (Tesis)", Universitas Hasanuddin, Makassar, 2014.

[5] Muhira Dzar Faraby, "Penggunaan Algoritma Genetika Dalam Mengoptimalan Penempatan SVC Pada 
Sistem Kelistrikan Sulselbar

Berdasarkan RUPTL PT. PLN

Persero", SNTEK, Gowa, 2016.

[6] Marsudi Djiteng, "Operasi Sistem

Tenaga Listrik", Graha Ilmu, Jakarta, 2016. 